\title{
Tackling the Stiglitz Report: Measuring Social Progress and Economic Performance under Various Climate Policy Scenarios
}

\author{
Koji Tokimatsu ${ }^{1,2^{*}}$, Rieko Yasuoka ${ }^{3}$, Masahiro Nishio ${ }^{2}$ \\ ${ }^{1}$ Tokyo Institute of Technology, Yokohama, Japan \\ ${ }^{2}$ National Institute of Advanced Science and Technology, Tsukuba, Japan \\ ${ }^{3}$ System Research Center Co. Ltd., Tokyo, Japan \\ Email: *tokimatsu.k.ac@m.titech.ac.jp
}

How to cite this paper: Tokimatsu, K., Yasuoka, R. and Nishio, M. (2019) Tackling the Stiglitz Report: Measuring Social Progress and Economic Performance under Various Climate Policy Scenarios. Modern Economy, 10, 2209-2231.

https://doi.org/10.4236/me.2019.1011139

Received: September 28, 2019 Accepted: November 17, 2019

Published: November 20, 2019

Copyright (c) 2019 by author(s) and Scientific Research Publishing Inc. This work is licensed under the Creative Commons Attribution International License (CC BY 4.0).

http://creativecommons.org/licenses/by/4.0/

\begin{abstract}
This paper attempts to connect the measurement of social progress from the Stiglitz report and climate change mitigation (CCM) by the Intergovernmental Panel on Climate Change (IPCC) assessment reports. Each report has been addressed insufficiently on the issue, although both reports have common interests in development patterns and pathways for the economy, humanity, and society. This study used our original integrated assessment model and applied for measuring various indicators for sustainable development, such as genuine savings (known as GS) and human appropriation of net photosynthetic primary production (HANPP). We expanded an analysis of sustainable development indicators of quality of life (QoL) and of the human development index (HDI) and introduced a modified quality of life indicator. These indicators expand on the "classical" GDP loss, which has been well analyzed in the majority of CCM literature. Our model's main framework is based on the Regional Integrated model of Climate and the Economy (RICE) extended from Ramsey-Cass-Koopmans with a simplified climate model and added three original resource balance models with environmental consequences with a life cycle impact assessment (LCIA) model. We prepared various climate policy scenarios ranging from business as usual to economically efficient, $\mathrm{CO}_{2}$ double stabilization, and targeting two degrees Celsius (DC). We believe this work has three contributions. First, in contrast with the World model by the Limits to Growth, our model has an economic foundation where genuine savings is introduced. Second, while the Stiglitz report only extrapolates the current genuine savings trend, we are able to calculate the future trajectories of sustainable development indicators, based on a sophisticated integrated assessment model. Third, when compared to the RICE analysis, which sought the optimal climate policy in the sense of cost-benefit analysis, our model in-
\end{abstract}


troduces indicators of sustainable development in assessing climate policies.

\section{Keywords}

Stiglitz Report, Integrated Assessment Model (IAM), Genuine Savings Human Development Index, Quality of Life, Net photosynthetic Primary Production

\section{Introduction}

The Stiglitz report [1] rests on three main pillars for reforming global monetary systems after the financial crisis of 2007-2008-classical gross domestic product (GDP), quality of life (QoL), and sustainable development and environment (SD \& E). GDP is the most used measure of economic activity globally. Although it primarily measures market production of economic activity in value-added terms, it is commonly used as a measure of economic well-being. Material standards of living, however, are more closely associated with measures of real income and consumption rather than production. Because of the various limitations (fully described in the report), alternative ways to measure social progress other than economic performance are presented in the report.

The measurement of QoL is categorized into three approaches: subjective well-being (SWB), capabilities, and welfare economics and fair allocations. SWB includes three separate aspects: life satisfaction, the presence (and absence) of positive feelings, and the presence (and absence) of negative feelings. Two representative measurement approaches are the World Value Survey (a qualitative survey) and the Gallup World Poll (a quantitative survey with a 0 to 10 quality-of-life scale). Quality of life is comprised of material living standards (e.g., income), health, education, personal activities (e.g., paid and unpaid work, commuting, leisure time, and housing), political voice and governance, social connection, environmental condition, and insecurity. These conditions can be functioning (people's doings, e.g., working and commuting, and people's being, e.g., healthy and educated) or freedom (e.g., political voice and participation). The human development index (HDI) has a capability approach in terms of a person's freedom to choose among the various combinations of functioning factors. The HDI is the representative indicator aggregating across those various domains, specifically health, education, and living standards.

SD \& E covers various economic and environmental indicators-things like dashboards or composite indexes, adjusted GDP, adjusted net savings (ANS), and ecological footprint (EF). As recommended in the Stiglitz report (Message 1, p. 263 of the report), measuring SD \& E requires future projections as well as historical observations. Appendix 3 of the report (pp. 280-282) shows some modifications on ANS estimates up to the year 2030 with trends observed since 1990 or remaining constant at the 2006 level in ANS, excluding $\mathrm{CO}_{2}$ damage or its intensity ratio $\left(\mathrm{CO}_{2}\right.$ emissions per units of GNI). Appendix 4 of the report 
(pp. 283-287), titled "More on the ANS and Climate Change", offers economic valuation of global warming consequences by so-called climate welfare economy integrated assessment models (IAMs). It illustrates some of the narrative and dynamic scenarios on ANS with and without a climate policy.

None of the qualitative in-depth investigations by IAMs, however, have been addressed in the report. Contrary to this, climate policy assessment has long been analyzed only by "classical" loss of GDP or the social cost of carbon (SCC) (calculated as the present value of discounted economic welfare loss by a marginal GHG emissions increase) [2]. These factors are categorized as "economic performance" in the report. This article tackles the projection issue under climate policy scenarios using the measuring indicators of QoL and SD \& E in our IAM. The authors have long been studying the latter issue (i.e., measuring future projections of indicators in SD \& E), especially on ANS (or GS) and HANPP ${ }^{1}$ [4] [5] as a proxy of "carrying capacity" instead of $\mathrm{EF}^{2}$. Recently, Pezzey and Burke [10] addressed a "precautionary" approach by modifying the "highly aggregated" damage function in the original DICE model and deriving a recently well-defined SCC to amend ANS in the present day with and without the climate policy. Compared with those results, the projection of the former (i.e., QoL indicators) has not been addressed to the authors' knowledge, a topic this article addresses intensively. We examine future projections of ANS and HANPP for the SD \& E using well-defined HDI, modified indicators for QoL, and GDP for "classical" economic performance.

The organization of this article is as follows. Section 2 gives short reviews on the theoretical background and measurement issues for the economic and environmental indicators. Section 3 describes our IAM and calculation of the indicators. This is followed by results, discussion, and conclusions in Sections 4, 5, and 6 , respectively.

\section{Literature Review}

\subsection{SD \& E}

\subsubsection{Weak Sustainability (ANS or GS)}

Genuine Savings (GS) was established as a comprehensive indicator of sustainability in successive theoretical contributions-from early studies by Dasgupta and Heal [11], Solow [12], Stiglitz [13], and Hartwick [14] to more recent contributions by Weitzman [15], Pezzey [16], and Dasgupta [17]. Empirically, Pearce ${ }^{1}$ Net photosynthetic production means the accumulation of biomass in plants [3]. Photosynthetic production is the production of organic compounds from atmospheric or aquatic carbon dioxide. It may occur through the process of photosynthesis, using light as a source of energy, or through chemosynthesis, using the oxidation or reduction of chemical compounds as a source of energy.

${ }^{2} \mathrm{EF}$ was excluded for three reasons. One was that we could not find an appropriate methodology to obtain the yield factor and the equivalence factor required to calculate EF using our model. On the contrary, the potential NPP to use to calculate HANPP is scientifically evident, as it is determined by temperature and precipitation. Another reason not to use EF was that EF is most appropriate for high-resolution analysis, such as those conducted at the country or mesh level [6] [7]. In our model with ten large regions could not calculate and present EF for such a high spatial resolution. The third reason is that previous studies have already presented the future trends of EF [8] [9]. 
and Atkinson (1993) [18] coined the term GS, succeeded by a series of contributions from Hamilton [19], Hamilton and Clemens [20], the World Bank [21] [22] [23], and Hanley et al. [24]. A detailed presentation of both theory and practical use of GS can be found in Hanley et al. [24].

GS is effectively the rate of change of the total wealth available in an economy. This total wealth is understood as comprehensive wealth, that is, the economic value of all the capital stocks with and without market value in a given economy. GS therefore integrates all of the changes (impacts) that alter the ability of an item to yield its services.

GS is grounded in the standard utility theory; as a result, it is easily incorporated into the DICE model [25]. Intergenerational well-being, $V_{t}$ is expressed in Equation (2.1-1) by using instantaneous utility, $U_{t}$ and the utility discount rate $\rho$.

$$
V_{t}=\int_{t}^{\infty} U_{t}(C(s)) \mathrm{e}^{-\rho(s-t)} \mathrm{d} s
$$

"Sustainable development" as presented in the WCED report [26] can be interpreted as a pattern of societal development along which intergenerational human well-being does not decline. Formally, development is sustainable if well-being is sustained over time, that is, $\mathrm{d} V / \mathrm{d} t \geq 0$.

Comprehensive wealth is defined in Equation (2.1-2), where $W_{t}$ is comprehensive wealth valued using the shadow prices of the three capital stocks. Genuine Savings is then the rate of change of capital stocks, valued at their shadow prices, as shown in Equation (2.1-3).

$$
\begin{gathered}
W_{t}=\frac{\partial V_{t}}{\partial K_{t}} K_{t}+\frac{\partial V_{t}}{\partial H_{t}} H_{t}+\frac{\partial V_{t}}{\partial P_{t}} P_{t} \\
G S_{t}=\frac{\partial V_{t}}{\partial K_{t}} \frac{\mathrm{d} K_{t}}{\mathrm{~d} t}+\frac{\partial V_{t}}{\partial H_{t}} \frac{\mathrm{d} H_{t}}{\mathrm{~d} t}+\frac{\partial V_{t}}{\partial P_{t}} \frac{\mathrm{d} P_{t}}{\mathrm{~d} t}
\end{gathered}
$$

Two methods produce empirical estimates of the theoretical notions of "Genuine Savings" and "Comprehensive Wealth." The first method, Genuine Savings, which is outcome based, is used by the World Bank, while the second method, Comprehensive Wealth, which is capability based, has been used by the $\mathrm{UN}$ in a series of reports on inclusive wealth based on Arrow et al. [27]. See Hanley et al. [24] for more details.

The merits of both approaches are now routinely debated in the literature, as exemplified by the 2012 special issue of Environmental and Development Economics [27] [28] [29] [30] [31] and the 2014 special issue of the Oxford Review of Economic Policy (e.g., Hamilton and Hartwick 2014 [32]). Pezzey and Burke [10] offered a contribution that is quite close to the aim of this paper; they used the World Bank method but amended GS for the physical constraints associated with global warming and offered a more realistic estimation of the costs associated with uncontrolled climate change.

\subsubsection{Carrying Capacity (HANPP)}

Attention was first paid to HANPP in the 1970s to raise the concern over excessive human economic activities (Whittaker and Likens, 1973) [33]. Vitousek first 
made HANPP popular with economic academicians and ecologists [4]; that work triggered many quantitative analyses for HANPP. However, the results differed widely because of the application of different mathematical definitions of HANPP. In the Special Issues of Ecological Economics in 2009, which included the paper by Erb et al. [5], HANPP was defined as the difference between the potential NPP and the actual level of NPP in land use, the same definition that Vitousek offered in 1986 [4].

NPP provides ecosystem services through agriculture and forestry, some of which can replace fossil fuel products (e.g., biofuels). Moreover, it also has a capacity to absorb exhaust emissions. NPP also serves as a buffer for waste products [5]. Since NPP is affected by changes in land use that have critical impacts on biodiversity, HANPP may be considered as a strong indicator of sustainability; it can express natural capital that is hard to substitute with physical capital. HANPP also expresses resilience because it is related to the cycle of water, carbon, and nitrogen as well as the deposition of organisms in the soil that increases land productivity.

\subsection{Quality of Life}

\subsubsection{The Well-Defined HDI}

The foundations of the capability approach taken by HDI are strongly rooted in philosophical notions of social justice; they focus on human ends and on respecting an individual's ability to pursue and realize personal goals. The HDI is the geometric mean of normalized indices for each of the three dimensions as a proxy of human development, namely, having a long and healthy life, being knowledgeable, and having a decent standard of living. The health dimension is assessed by life expectancy at birth (LEB); the education dimension is measured by the mean of years of schooling (MYS) for adults aged 25 years and older and the expected years of schooling for children of school-entering age. The standard of living dimension is measured by GNI per capita. The HDI uses the logarithm of income to reflect the diminishing returns from increasing GNI. The scores for the three HDI dimension indices are then aggregated into a composite index using the geometric mean. This is illustrated in Equations (2.2-1) through (2.2-6) [34].

$$
\begin{gathered}
\text { Health index }=\left(\mathrm{LEB}_{j, t}-20\right) /(85-20) \\
\text { Education index }=(\text { EYS index }+ \text { MSY index }) / 2
\end{gathered}
$$

where the EYS index (expected years of schooling $)=\left(\mathrm{EYS}_{j, t}-0\right) /(18-0)$

$$
\text { MYS index }=\left(\text { MYS }_{j, t}-0\right) /(15-0)
$$

$$
\text { Income index }=\left[\ln \left(\mathrm{GNI}_{j, t} / \mathrm{cap}_{j, t}\right)-\ln (100)\right] /[\ln (75000)-\ln (100)]
$$

$$
\mathrm{HDI}=[(\text { Health index }) *(\text { Education index }) *(\text { Income index })]^{1 / 3}
$$

This mathematical expression has well-known limitations. One limitation is 
the weighting among the three dimensions in applying the geometric mean; notably, that weighting the importance of the three dimensions implies is an arbitrary value judgment. Because of this algorithm, HDI's movements have tended to be dominated by changes in the GNI component, at least for developed countries (such as France and the United States) with high performance in the health and education domains. Another limitation is applying logarithm (or nonlinear) GNI/cap; it implicitly values an additional year of LEB in each country by its GNI/cap (the higher income like that in the United States has greater value than the lower income of India or Tanzania).

\subsubsection{Modified Quality of Life Indicator $\left(\mathrm{Q} o \mathrm{~L}_{\mathrm{fa}}\right)$}

To overcome shortcomings in the well-established HDI, a modified QoL indicator is proposed [35] that applies a linear function composed of six variables with coefficient covering the three domains, namely, health (infant health rate (IHR) which equals the infant mortality rate (IMR)), improved water access (IWA), LEB, education (MSY), and the standard of living (GDP, GNI, both on a per capita basis). Unlike the arbitrary weighting in HDI, the factor analysis (FA) method enables us to derive the linear function with simultaneously generated coefficients for the variables. The advantage in employing the equation is overcoming the shortcomings of HDI, as described in Section 2.2.1. $\mathrm{QoL}_{\mathrm{fa}}$ can be characterized as the nonlinearity among the different domains with arbitrary weighting that expands variables related to climate change (i.e., IWA), yet is still based on the philosophy of HDI. The equations are as follows:

$$
\begin{aligned}
\mathrm{QoL}_{\mathrm{fa}}= & 0.828 * \mathrm{MYS}+0.918 * \mathrm{GDP}+0.925 * \mathrm{GNI} \\
& +0.913 * \mathrm{IHR}+0.910 * \mathrm{LEB}+0.685 * \mathrm{IWA} \\
\mathrm{QoL}_{\mathrm{fa}}= & 0.831 * \mathrm{MYS}+0.878 * \mathrm{GDP}+0.932 * \mathrm{IHR} \\
& +0.924 * \mathrm{LEB}+0.714 * \mathrm{IWA}
\end{aligned}
$$

omitting GNI term.

\section{Methodology}

\subsection{The Model}

\subsubsection{Representative Agent}

Our modeling strategy is based on an IAM, combining a RICE model for climate change assessment with the LCIA model (named LIME, life cycle impact assessment method based on endpoint modeling [36] [37]. For a detailed description, see Tokimatsu et al. [38]. The world economy is divided into $n$ regions, and each region $j$ is composed of identical individuals, who maximize utility through the consumption of a composite good:

$$
u\left(c_{j, t}\right)=\left\{\begin{array}{l}
\frac{C_{j, t}^{1-\eta}}{1-\eta}(\eta \neq 1) \\
\log c_{j, t}(\eta=1)
\end{array}\right.
$$

where $u\left(c_{j, t}\right)$ is the per capita utility of consumption in region $j$ at time $t$. The 
parameter $\eta$ is the elasticity of the marginal utility of consumption ${ }^{3}$. The total regional utility, $u\left(c_{j, t}\right)$, is obtained by multiplying individual utility by $P_{j, t}{ }^{4}$, the exogenously given population number for region $j$ in time $t$. We then sum the regional total utility for all future time periods $s$ over the time horizon $T$ to obtain intertemporal well-being, $V_{j, t}$, shown in Equation (3.1-2).

$$
V_{j, t}=\sum_{t}^{T} P_{j, s} u\left(c_{j, s}\right) \rho^{(s-t)}
$$

where $\rho$ is the pure rate of time preference, reflecting how future generations' well-being is taken into account. Each region is assumed to produce a single commodity, which can be used for either "generalized" consumption or investment as economic variables. The generalized consumption includes not only traditional market purchases of goods and services but also nonmarket consumption, such as enjoyment of the environment. Finally, regional-level intertemporal well-being, $V_{t}$ is maximized at the aggregate level via the function $W_{t}$ in Equation (3.1-3):

$$
\max W_{t}=\sum_{j}^{n} N e g_{j} V_{j, t}
$$

where $W_{t}^{5}$ is the objective function weighted sum of social welfare, $V_{j, t}$, for region $j, t$ by Negishi weight, $\mathrm{Neg}_{j}{ }^{6}$. The use of Negishi weights means that the distribution of well-being is kept constant over time, preventing convergence in consumption levels.

\subsubsection{Production}

Gross output is determined by a nested production function, with capital, labor, and natural resources as inputs:

$$
F\left(A_{j, t}, K_{j, t}, H_{j, t}, E L_{j, t}, N E_{j, t}, M_{j, t}, L R_{j, t}\right)
$$

where $A_{j, t}$ is the exogenously given total factor productivity term, $K_{j, t}$ is physical capital, $H_{j, t}$ is human capital, $E L_{j, t}$ is electricity, $N E_{j, t}$ is nonelectric energy, $M_{j, t}$ denotes nonfuel mineral resources, and $L R_{j, t}$ denotes land resources.

We assume that all transfers of production factors across regions happen through investment and divestment: there are no lump sum transfers of capital, making it effectively immobile. Physical capital accumulation and depreciation happen only through the usual equation of motion:

$$
K_{j, t+1}=(1-\delta) K_{j, t}+I_{j, t}
$$

where $\delta$ is the annual rate of capital depreciation. In line with our representa${ }^{3}$ It also represents the curvature of the utility function, or the rate of inequity aversion, measuring the extent to which a region is willing to reduce the welfare of high consumption generation and to improve that of low consumption generation.

${ }^{4}$ The given population number, $P_{j, t}$, is taken from the SSP-2 scenario in order to coherently analyze climate change mitigation. The number is the largest among the five SSP scenario families [39], somewhat higher than the UN's [40] mid projection but still close to the central level compared with high and low projections.

${ }^{5} t \geq 0$, with time steps of 10 years from 2010 to 2150 . We use steps of ten years to give enough time for the changes to happen in real life, following the World Bank view on wealth accounting.

${ }^{6}$ The Negishi technique is referenced from Nordhaus and Yang (1996) [41]. 
tive agent assumption, we take population growth and technological change to be exogenous. Technological change in the model is divided in two parts: the exogenously given TFP and the evolution of the mix of inputs used in the production process.

$$
A_{j, t+1}=A_{j, t}\left(1+\tau_{j, t}\right)
$$

where $A_{j, t}$, the TFP, is determined every period based on the exogenous TFP growth rate, $\tau_{j, t}$. Capital accumulation and natural resource inputs are then determined by maximizing the discounted utility flow over time constrained by the technology mix (the production function). Net output is then given by:

$$
Y_{j, t}=F_{j, t}-T C_{j, t}-E X T_{j, t}
$$

The net output Equation (3.1-7) ties together the three components in Figure 1:

The macroeconomic model in the red box determines gross output, based on the cost of resource acquisition, $T C_{j, t}$, as determined in the blue box. Available output is then reduced by an estimation of the external cost of production, $E X T_{j, t}$, which is determined by the LCIA model (yellow box) to get net output, $Y_{j, t}$. Further details on $T C_{j, t}$ and $E X T_{j, t}$ are provided below. There is interregional trade of the final good, and trade is not balanced. Thus, the accumulated trade surplus/deficit of each region is not necessarily zero in any period, including the final period. The budget constraint for the representative agent in each region is therefore:

$$
Y_{j, t}=C_{j, t}+I_{j, t}+M_{j, t}-X_{j, t}
$$

With the imports, $M_{j, t}$, and the exports, $X_{j, t}$, interregional trade is then balanced globally, by the next equation:

$$
\sum_{j}^{n} M_{j, t}=\sum_{j}^{n} X_{j, t}
$$

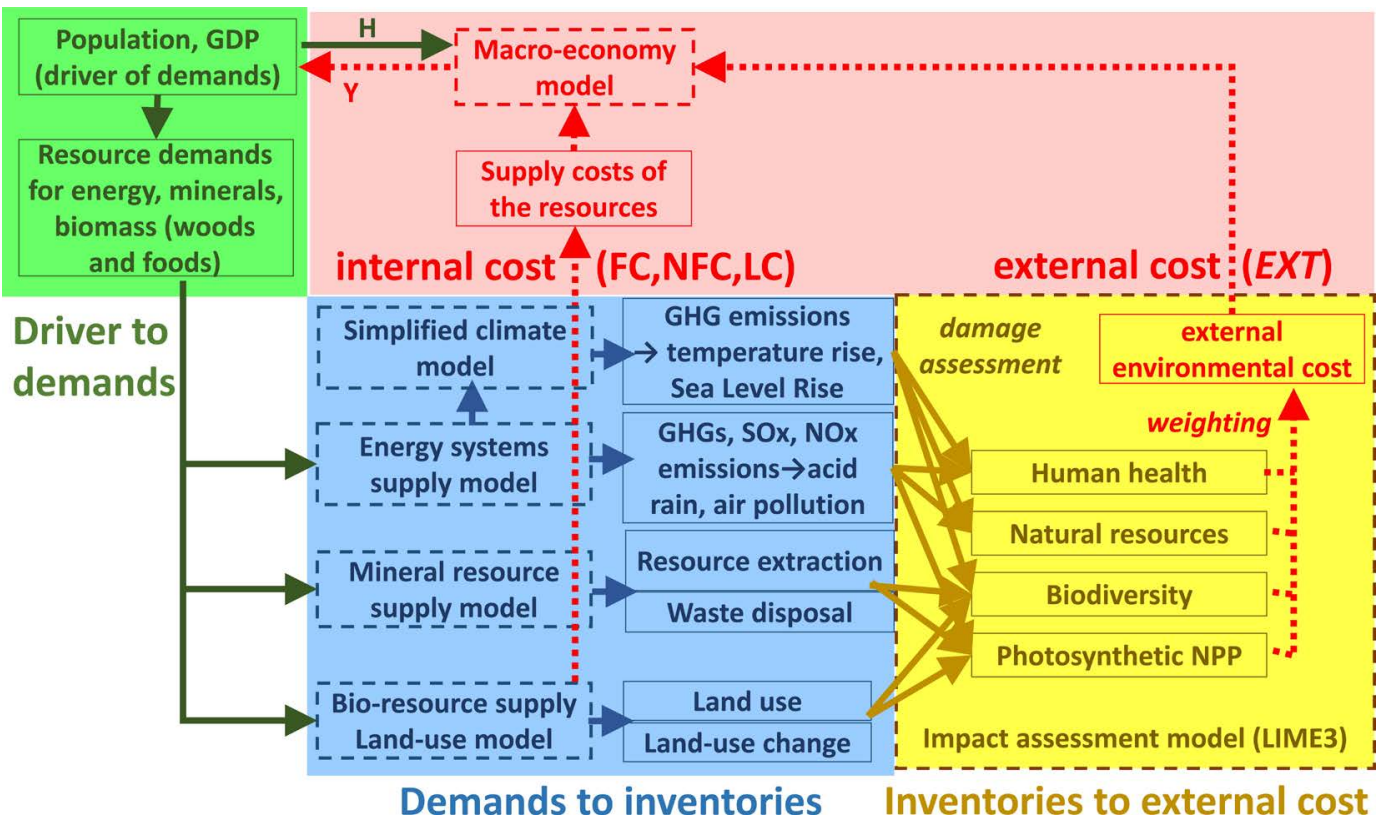

Figure 1. The structure of the model. 
Because trade is not constrained by a requirement to be balanced at any time, exogenous constraints reflecting the feasible evolution of consumption and investment are imposed every period for every region $j$. The net output is allocated between generalized consumption $C_{j, t}$, and investment in physical capital, $I_{j, t}$, in a way that maximizes the aggregate (world level) well-being, $W_{t}$. The level of $Y_{j, t}$ that is selected is associated with a cost and a level of environmental impact in the blue and yellow parts of the model.

\subsubsection{Costs of Production}

The total cost of production, $T C_{t}$ comes from the three models of resource balance in the blue box (Figure 1). These models tie together supply and demand to generate inventories. These inventories are then used as factor endowments in the production function $\left(E L_{j, t}, N E_{j, t}, M_{j, t}, L R_{j, t}\right)$, while their direct cost of extraction/production is accounted for in $T C_{t}$ (see Equation (3.1-10)). The climate model is adapted from the RICE 2010 model [42]. Descriptions of the energy model, the mineral model, and the simplified land use for biomass and food model can be found in our previous contributions [43] [44] [45].

For simplicity, each model generates one final total cost, which is the product of cost minimization using dynamic linear programing. In Equation (3.1-10), $F C_{j, t}$ is the production cost of fuel, $N F C_{j, t}$ is the cost of nonfuel resources, and $L C_{j, t}$ is the cost of land resources. Formally,

$$
T C_{j, t}=F C_{j, t}+N F C_{j, t}+L C_{j, t}
$$

The external cost of production, $E X T_{t}$, comes from the LCIA model, LIME3, shown in the yellow box in Figure 1. While the overall cost of extraction, $T C_{j, t}$, is a direct consequence of the demand for natural capital, there are other impacts associated with environmental degradation. These impacts are determined against endpoints $E P_{j, t}$ that represent the societal goals associated with sustainability. The inventories generated by the resource balance models form the basis of the impact assessed here. The external cost is computed as:

$$
E X T_{j, t}=\sum M W T P_{j, t} \sum D R_{j, t} \operatorname{Inv} v_{j, t}=\sum M W T P_{j, t} \cdot E P_{j, t}
$$

The external cost is best understood as a stock/impact/value relationship. $I n v_{j, t}$ (stock) represents inventory releases, which can be expressed as a function of $P_{t}$ (e.g., $\mathrm{CO}_{2}$ emissions via transformation of energy resources stock changes, land cultivation and waste disposal by mining, and disposal of mineral resources). $D R_{j, t}$ (impact) is a function to express the dose-response relationship (or cause-effect chain) [46]-[52] that relates the damages at the four endpoints to their causes, expressed as $\operatorname{In} v_{j, t}{ }^{7}$.

${ }^{7}$ Three examples are provided as illustration. The impacts of global warming on human health are expressed by the relative risk increase due to a rise in the global mean temperature $(T(t))[48]$. The economic impacts of land loss by sea level rise (SLR) $(S L R(t))$ are similar to those assessed by Fankhauser [53] and Tol [54]. Land use and land-use change are caused by biomass and food production, which can be expressed generally as $L U(t)$. $T(t)$ and $S L R(t)$ are obtained from the same formulations in RICE 2010: total carbon emissions from fossil fuel combustion in energy systems [43], carbon released from land-use change [44] and exogenously given non- $\mathrm{CO}_{2}$ GHGs. 
$M W T P_{0}$ is a set of marginal willingness to pay (MWTP) associated with the endpoints. We use MWTP instead of estimating a damage function because an estimation of an aggregated function is ill-suited to our disaggregated modeling structure. See Itsubo et al. [37], Tokimatsu et al. [55], Murakami et al. [56] and Kolstad et al. [57] for more details.

\subsection{Data and Calibration}

The discrete time step of the model is 10 years, and 10 regions are included: North America, Western Europe, Japan, Oceania, China, Southeast Asia (the Association of Southeast Asian Nations (ASEAN) member countries, plus India), the Middle East and North Africa, sub-Saharan Africa, Latin America, and the former Soviet Union and Eastern Europe. The population is assumed to be composed of representative agents, with the size estimations based on UN projections from the Shared Socioeconomic Pathways (SSP)-2 scenario [39]. Population data $\left(P_{j, t}\right)$ and the reference level $\left(\bar{Y}_{j, t}\right)$ of the GDP scenario are taken from the SSP database (version 0.9.3) [58], in which IIASA-WiC population and OECD GDP are applied.

Regarding the labor population $\left(L_{j, t}\right)$, we computed the population rate at each time period for each region, based on a medium-scenario population projection by the United Nations [40] [59]. We subsequently multiplied these figures by the population data $\left(P_{j, t}\right)$. Calibration data for $C, I, Y, M, X$, in 2010 and $\delta$ (set from $7 \%$ to $18 \%$ per annum) for the respective regions were obtained from the World Development Indicators (WDI) [23] and the Global Trade Analysis Projects (GTAP) database (Purdue University, 2015) [60].

The setting of the initial $K$ value was obtained from the RICE 2010 model [42]. We used a nested CES production function inspired by Berndt and Wood [61] and Manne and Richels [62] in a departure from the usual specifications in RICE-99 or RICE-2010 [42] [63]. $M W T P_{0}$ was derived from the discrete choice experiments used in environmental valuation, and those data were obtained from both face-to-face and Internet surveys in G20 [37] [56] and Asian countries [55].

The utility discount rate, $\rho$, is assumed to be $1.5 \%$ per annum, in the lower end of the range in the literature $(0.1 \%$ - 5\%) [64] [65] [66] [67]. Capital depreciation was set as.07 to. 18 depending on the region. Since the time period of our model is assumed to be 10 years, we used the tenth power of the annual rate in the equation.

TFP was calibrated from data sources to fit the scenarios (level of production). The form of function $\phi$ is increasing but diminishing in rate $\left(\phi^{\prime}=\mathrm{d} \phi / \mathrm{d} S>0\right.$, $\phi^{\prime \prime}=\mathrm{d}^{2} \phi\left(\mathrm{d} S^{2}<0\right)$, where $\phi$ equals 0 when $S$ is 0 . Here, $\phi^{\prime}$ denotes the marginal income increase by additional education attainment, corresponding to the coefficient (rate of return); $\phi^{\prime}$ was determined using data from various studies [68] [69] [70] [71] [72] [73].

We did not follow DICE 2013 for the initial values for the TFP level $\left(A_{j, 0}\right)$ 
and growth rate $\left(\tau_{j, t}\right)$. We calibrated the TFP growth rate based on the future baseline scenario (SSP-2) to obtain feasible solutions for computation. In some sections, we applied historical data from Klenow [73]. We calculated the TFP to determine not only $A_{j, 0}$ but also the values over the time horizon from the results of the SSP-2 scenario.

First, we obtained $A_{j, t}$ from the solution of Equation (3.1-7), shown here in expanded form:

$$
\bar{Y}_{j, t}=\left(A_{j, t}, K_{j, t}, H_{j, t}, E L_{j, t}, N E_{j, t}, M_{j, t}, L R_{j, t}\right)-\left(F C_{j, t}+N F C_{j, t}+L C_{j, t}\right)
$$

where $\bar{Y}_{j, t}$ is the GDP of SSP-2 and the other selected variables are endogenously calculated in the model. Subsequently, regression analysis was conducted from the obtained variable $A_{j, t}$, to derive the initial level $\left(\tau_{j, 0}\right)$ and the decline rate of the TFP. The derived TFP is given as a constant parameter throughout our simulations.

\subsection{Scenarios}

The model as presented so far is the baseline scenario. In this setting, all externalities are internalized, and all of the parameters are set at their base level. This is called the economically efficient scenario (Eeff). The incentives to reduce $\mathrm{CO}_{2}$ emissions are based on their direct and indirect cost through $T C_{j, t}$ and $E X T_{j, t}$. Next to the baseline, we define a business as usual (BAU) scenario. Under BAU, the externalities associated with the endpoints have not been taken into account by the social planner; therefore, $E X T_{j, t}=0$. Then, the budget constraint in 3.1-8 becomes:

$$
Y_{j, t}=F_{j, t}-T C_{j, t}
$$

Our third and fourth scenarios are based on opposite trajectories for carbon emissions. The $\mathrm{CO}_{2}$ double scenario $\left(\mathrm{CO}_{2}\right)$ is obtained by adding the cumulative emissions from 2010 to 2150 of the WRE-550 scenario [74], resulting in an atmospheric concentration of $\mathrm{CO}_{2}$ of $550 \mathrm{ppm}$. The zero emission scenario (ZERO) implements the 2-degree Celsius (DC) target, imposing cumulative emissions of zero over the time horizon. This is made possible by allowing positive emissions over the coming several decades that would be balanced out by negative emissions in the latter half of the century.

\subsection{Calculating Indicators}

\subsubsection{GS}

We then computed GS ex post following the method used by the World Bank [22]. The method focuses on the definition of comprehensive investment as:

$$
G S_{j, t}=\left(I_{j, t}-\delta K_{j, t}\right)+\left(\operatorname{Im}_{j, t}+I e_{j, t}\right)-\sum M W T P_{j, t} \cdot E P_{j, t}-\sum S P_{j, t} \cdot \operatorname{In} v_{j, t}
$$

In line with the theoretical definition in Equation (2.1-3), GS is the rate of change in capital stocks, at current shadow prices. $I_{j, t}$ is investment in physical capital, $\delta K_{j, t}$ is the depreciation of physical capital, $\operatorname{Im}_{j, t}$ is investment in 
health capital ${ }^{8}, \quad I e_{j, t}$ is investment in human capital, $\sum M W T P_{j, t} \cdot E P_{j, t}$ is the depletion of exhaustible resources (natural capital), and $\sum S P_{j, t} \cdot \operatorname{In} v_{j, t}$ is the indirect impact on the well-being of natural capital depreciation (environmental degradation). These values are calculated from simulation results using the following formulas:

- $I_{j, t}-\delta K_{j, t}$ was determined by Equation (3.1-5);

- $\quad I_{j, t}$ was estimated using a power function defined using the World Development Indicators (WDI). GDP values were then entered into that function to estimate the value of investment in medical expenses per capita. This per capita value is then multiplied by the population size in time $t$ to obtain the total investment value;

- $I e_{j, t}$ was estimated using a linear function defined using WDI. The $Y_{j, t}$ values were then entered into that function to estimate the value of investment in education per capita in year $t$. This per capita value was then multiplied by the population size in time $t$ to obtain the total investment value;

- $\quad I n v_{j, t}$ was the natural resource stocks and inventories obtained from the LIME3 and RICE components of our model.

The shadow prices associated with produced, human, health, and natural capital were the optimal prices obtained from our model. The $S P_{j, t}$ prices were computed as the rate of change in global well-being when the relevant inventory varies, over the change in well-being when consumption varies where $\operatorname{In} v_{j, t}$ was also taken straight from the model results as in Equation (3.1-11).

$$
S P_{j, t} \equiv \frac{\partial W / \partial \operatorname{Inv} v_{j, t}}{\partial W / \partial C_{j, t}}=\frac{W i n v_{j, t}}{W C_{j, t}}
$$

We have two sets of shadow prices, $M W T P_{j, t}$ and $S P_{j, t}$, for the two types of natural capital flows: direct flows from inventories and indirect flows from endpoints. We did not compute shadow prices for produced and human capital; instead, we directly added the full investment value. Our GS estimates were computed based on a 10-year step.

It should also be noted that due to the structure of the model, only $I_{j, t}-\delta K_{j, t}$ was derived directly from the optimization process. The other investment values were subtracted from the final level of consumption, based on net output.

The intuition was as follows: the representative agent set the level of net investment in produced capital which yielded the available produced capital stock in $t K_{j, t}$. During this first step, a gross level of consumption was set, from which investment in human capital and health capital should be deducted. The agent has no control over this lump sum subtraction to gross consumption, because the amount is exogenously set, proportionally to $Y_{j, t}$. The actual value of consumption is this net amount.

We can now define Genuine Savings as the rate of change in total wealth, by ${ }^{8}$ This stock and the respective investment are added in our computations to the World Bank methodology based on the suggestion of Arrow et al. [27]. 
first computing total wealth using the World Bank [22] method:

$$
W_{j, t, T}^{O B / W B}=\int_{t}^{T} C_{j}(t) \mathrm{e}^{-\rho(s-t)} \mathrm{d} s
$$

where $\rho$ is equal to 1.5 and $C$ is defined as sustainable consumption, that is $C$ minus $\operatorname{Im}_{j, t}$ and $I e_{j, t}$. Gross genuine savings is therefore:

$\Delta W_{j, t+1, T}$

$=\left[\left(I_{j, t+1}+I m_{j, t+1}+I e_{j, t+1}-\delta K_{j, t+1}\right)-\sum M W T P_{j, t+1} \cdot E P_{j, t+1}-E X T_{j, t+1}\right] / W_{j, t, T}^{O B / W B}$

This shows how wealth has increased between $t$ and $t+1$. We then adjusted this rate of change for population growth and technological progress (both exogenous in our model):

$$
\Delta W n t_{j, t+1}=\Delta W_{j, t+1}-p_{j, t+1}+\tau_{j, t+1}[\% / t]
$$

With $p_{j, t+1}$, the population growth rate ${ }^{9}$, and $\tau_{j, t+1}$, the technological progress growth rate, $\Delta W n t_{j, t \pm 1}$ is the notation for the final fully adjusted rate of change in wealth, or the "GS rate."

\subsubsection{HANPP}

The denominator of HANPP is the potential NPP, determined by temperature and precipitation [75]. The numerator of HANPP is NPP consumption by human activities. NPP consumption includes the direct and indirect consumption of foods, trees, and their residues, as well as the potential loss of NPP due to land use and land-use change (LU and LUC), caused by resource production activities. The three levels of NPP in the numerator in HANPP were provided in the papers by Erb [5] and Vitousek [4] as follows:

- Low estimate: Direct consumption (demanded quantity) of agricultural products (i.e., rice, wheat, corn), wood (i.e., logs, wood pulp, timber/boards, paper), and seafood eaten by humans and livestock;

- Middle estimate: The harvested amount from agricultural land, grassland, forests, etc., that produces the direct consumption (i.e., low estimate). This level is calculated as the sum of the direct consumption and conversion loss (unused residuals);

- High estimate: This is the sum of the middle estimate and the potential loss of NPP due to LU and LUC.

Direct consumption for the low estimate and the conversion loss in the middle estimate were calculated using our simplified land-use model. The potential NPP by 2100 that is needed to calculate the high estimate was obtained from the

\footnotetext{
${ }^{9}$ As population enters both the maximum and the production function in the macroeconomic model, GS should be adjusted [17]. The literature offers two methods for this. First, Ferreira et al. (2008) [76] consider future population growth as a form of capital loss, as future total wealth should be divided among a larger number of individuals. GS are amended two ways to make up for the capital loss: a reduction of the discount rate and a wealth-based subtraction to the gross GS rate. Second, Arrow et al. [27] consider exogenous population growth as one of the external dynamics of the economy, just like technological change. The GS amendment is then to subtract the population growth rate in t. As our production-based computation of GS savings is the replica of the Arrow et al. [27] method, we use this adjustment. Note that our population growth rate is not constant between 10 years' time steps, but it is constant within those 10 years' intervals.
} 


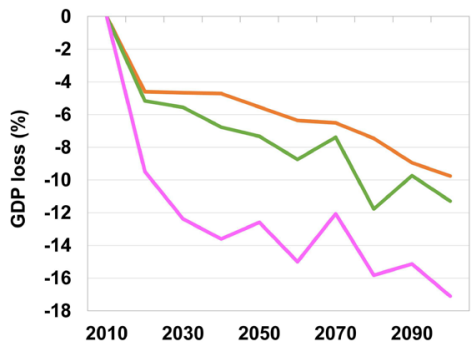

(a) GDP loss

Chikugo model [75], and it requires temperature and precipitation obtained from MAGICC/SCENGEN [77]. The changes in potential NPP due to LUC were calculated by multiplying damage factors for LUC with area change by LUC endogenously obtained from our land-use sub-model. This potential NPP is used as the denominator for the three estimates.

It should be noted also that our model does not have as high a resolution as the country or grid level using GIS, as seen in papers from the Special Issue of Ecological Economics in 2009 [5]. Instead, our model depicts the HANPP trend in line with the optimal economic development path.

\subsubsection{HDI and QoLfa}

We followed the equations from (2.2-1) to (2.2-6) in which $\mathrm{GNI}_{j, t}$ in $(2.2-5)$ is substituted for $\mathrm{GDP}_{j, t}$. $\mathrm{LEB}_{j, t}, \mathrm{EYS}_{j, t}$, and $\mathrm{MYS}_{j, t}$ were expressed by the semilogarithmic functions of GDP $\mathrm{G}_{j, t} / \mathrm{cap}_{j, t}$ The endogenously obtained GDP $\mathrm{G}_{j, t}$ was input into the functions to calculate the $\mathrm{HDI}_{j, t}$ where $j$ corresponds to the global level.

Similar functions in Equation (2.2-2) were derived for $\mathrm{QoL}_{\mathrm{fa}}(j, t)$ in (3.4-6) by factor analysis in each time step (i.e., $t=2010,2020, \ldots, 2100$ ), as expressed by Equation (3.4-6), from which a simple average is applied to indicate the global level. Similar semilogarithmic functions of $\mathrm{GDP}_{j, t} / \mathrm{cap}_{j, t}$ were also applied to $\operatorname{IHR}_{j, t}$ and $\operatorname{IWA}(j, t)$.

$$
\begin{aligned}
\mathrm{QoL}_{\mathrm{fa} j, t}= & a_{\mathrm{MYSt}} * \mathrm{MYS}_{j, t}+a_{\mathrm{GDPt}} * \mathrm{GDP}_{j, t}+a_{\mathrm{IHRt}} * \mathrm{IHR}_{j, t} \\
& +a_{\mathrm{LEBt}} * \mathrm{LEB}_{j, t}+a_{\mathrm{IWA}}(\mathrm{t}) * \mathrm{IWA}_{j, t}
\end{aligned}
$$

\section{Results}

Figure 2 shows the trajectories of the five indicators under the four climate

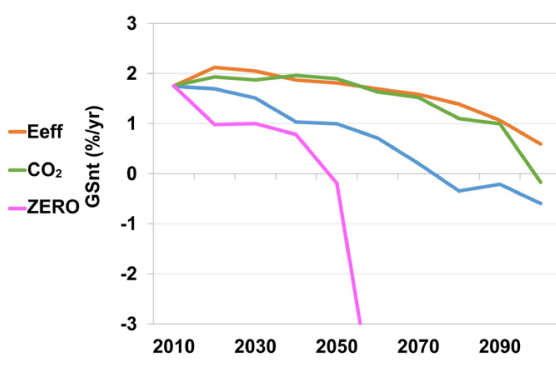

(b) GSnt

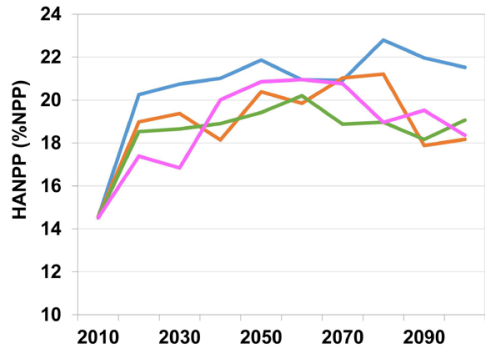

(c) HANPP

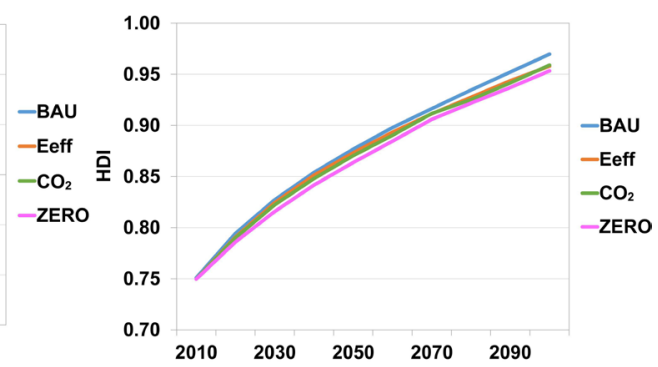

(d) HDI

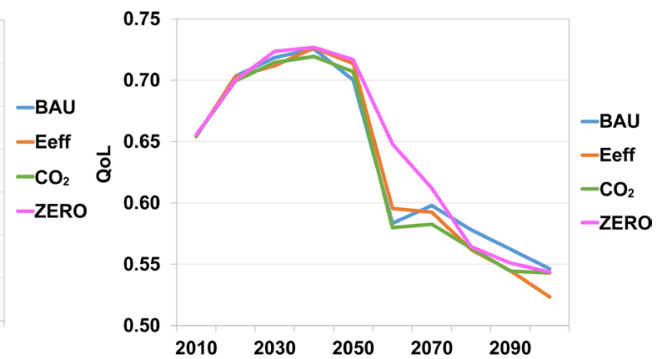

(c) QoL_fa

Figure 2. Future paths of all the five indicators under the four climate mitigation policy. 
mitigation policies. It is apparent that some scenarios show extreme changes, while others are less sensitive. The GDP loss shows a plausible trend along with the mitigation efforts: the more stringent, the larger loss. After confirming our model's behavior as a departure to examine the results, GSnt also shows the economically efficient path (denoted as Eeff) has the highest positive value, followed closely by the $\mathrm{CO}_{2}$ path. Furthermore, the business as usual line is far less level than those the prior two, while the ZERO scenario is collapsing to a negative level due to the rapid increase in various shadow prices; this suggests that the world might not accommodate such dramatic changes. HDI also shows a slight difference with consistent but not surprising trajectories: a higher GDP leads to higher HDI because its components are expressed as a function of per capita GDP. Unfortunately, our $\mathrm{QoL}_{\mathrm{fa}}$ has some difficulty in explaining the trajectory. The relative "rankings" of the global average among the ten regions are unclear because the global average shown in the figure is pulled down by the massive population in Southeast Asia and sub-Saharan Africa. Figure 3 and Figure 4 illustrate their changing rates versus $\mathrm{CO}_{2}$ growth rate (Figure 3), while Figure 4 shows both reduction rates from the baseline.

\section{Discussion}

The model in this study is original; it diverges from similar studies and highlights the significance of applying multiple indicator dimensions, namely, "classical" GDP loss, SD \& E in both WS (i.e., GS) and SS (e.g., HANPP), and QoL (e.g., HDI). Comparable studies explore future paths over the century of HDI by the World 3 model and the GS estimate by Pezzey and Burke [10].

Pezzey and Burke [10] modified the damage function in the DICE model to
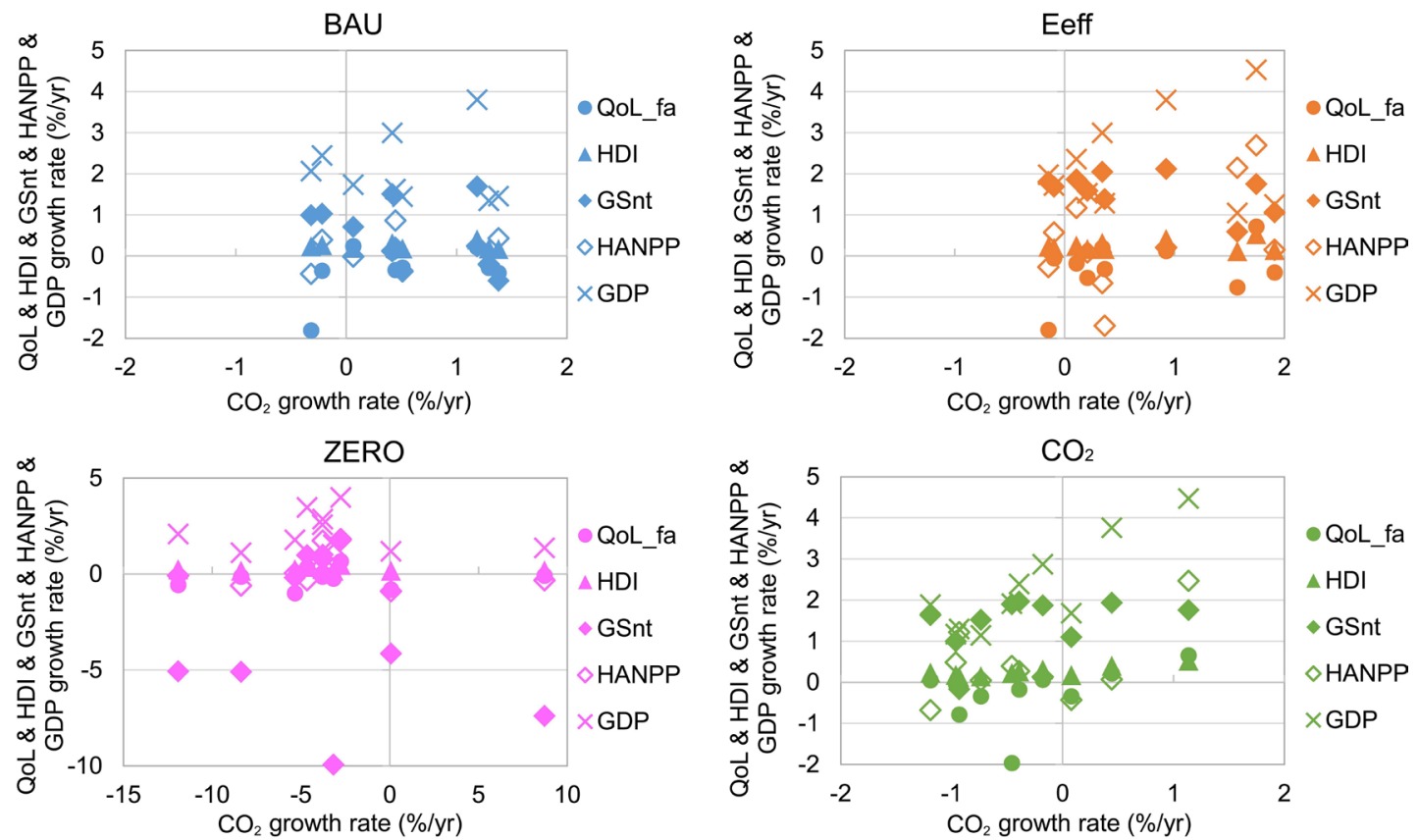

Figure 3. Changes in the four indicators with the four policies. 

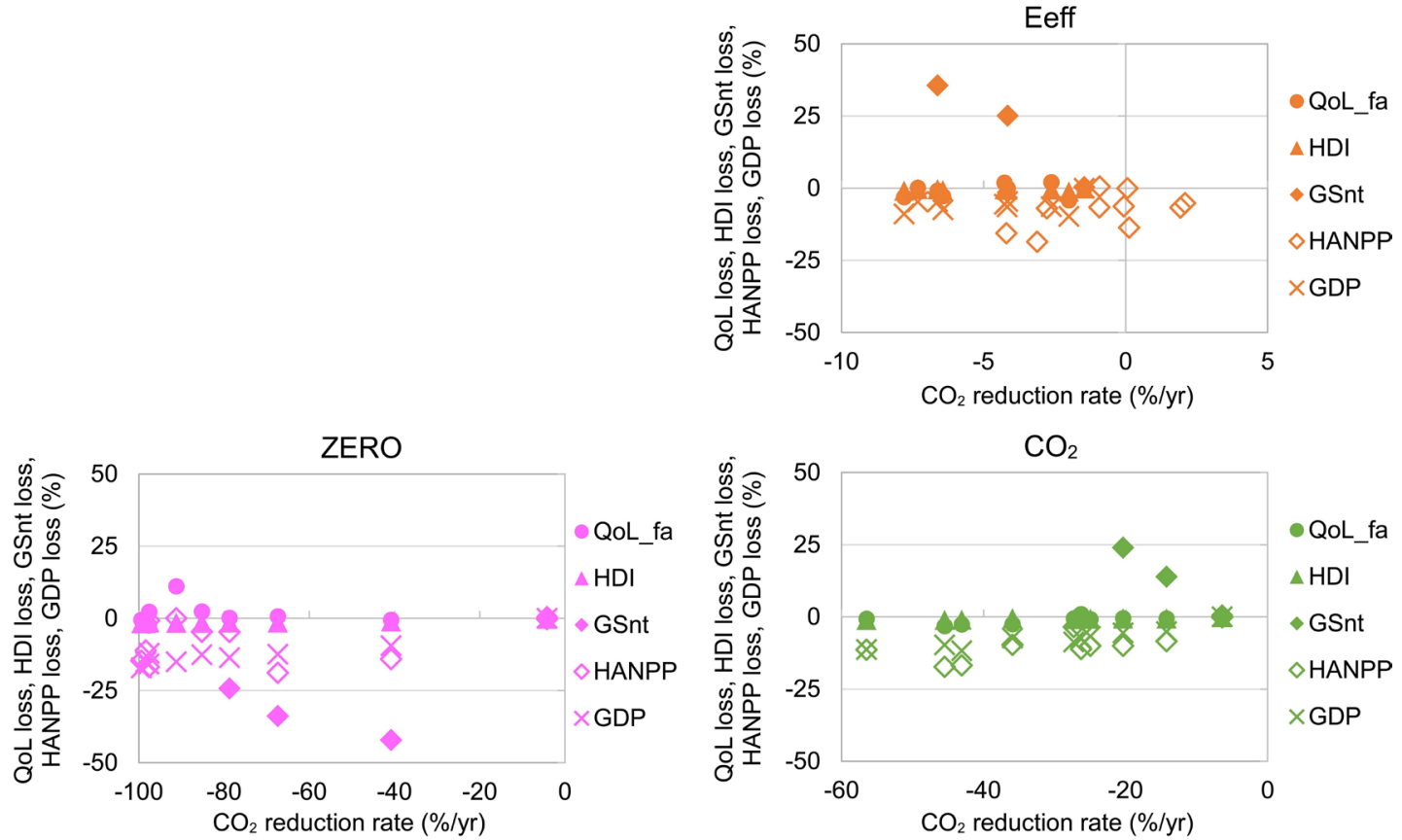

Figure 4. Reduction rate of the four indicators with the reduction rate from the baseline.

make a precautionary approach, with a similar aim as the 2-degree Celsius target; however, it did not show the trajectory of GS over time, but rather, it derived SCC (the current discounted marginal value of $\mathrm{CO}_{2}$ ), substituting the "environmental degradation" term in calculating GS.

No study has illustrated the future paths of those (or similar) indicators in SD \& E and QoL simultaneously (the World 3 model illustrates EF and HDI), and the literature on CCM mostly focuses on GDP loss. In this sense, this study is significant because it simultaneously illustrates multiple indicator dimensions.

We believe this work has three contributions. First, in contrast to the World model by the Limits to Growth, our model has an economic foundation that introduces GS. Nordhaus and Gordon criticized the World model because it lacked an academic foundation, especially economic theory and mineral resource data. This shortcoming, however, has been overcome by our modeling approach. The simulation technique (i.e., systems dynamics) employed by the World model "forecasted" the trajectories of "the economy", "HDI", "pollution", and "population". The nature of that technique nature led to "overshooting", leading to dismal outcomes. Compared to this, our model and GS are grounded by economic theory in a normative way (i.e., maximization of discounted utility flow).

Second, while the Stiglitz report simply extrapolates the current GS trend, we calculate the future trajectories of SD indicators based on a sophisticated IAM, as described above. Third, while the RICE model seeks the optimal climate policy in the sense of cost-benefit analysis, our model introduces SD indicators to assess climate policies. Nordhaus, the developer of the series of DICE/RICE models, had developed models for energy technologies [78] and copper [79]. Our IAM also includes state-of-the art models for energy, minerals, biomass and foods, in addition 
to an impact assessment model (i.e., LIME3) with dose-response (or cause-effect) functions in a bottom-up manner, contradicting the top-down aggregated damage functions.

\section{Concluding Remarks}

Our modeling exercise shows that we were not fully successful in operationalizing the QoL indicators for climate policy assessment because the trajectory of HDI is well synchronized to GDP level, and our original indicator QoL $_{\mathrm{fa}}$ shows unexplainable behavior. The behaviors seen in SD \& E indicators (GS, HANPP) are easier to interpret than QoL indicators, while GDP is the easiest to interpret. The paths suggest suitable operationalization for climate policy assessments in the current-day situation. Investigations on the choice and development of indicators, however, still do not fully respond to the social demands indicated in the Stiglitz report. Indicators for assessing climate policies are not yet operationalized.

\section{Conflicts of Interest}

The authors declare no conflicts of interest regarding the publication of this paper.

\section{References}

[1] Stiglitz, J.E., Sen, A., Fitoussi, J.P. (2009) Report by the Commission on the Measurement of Economic Performance and Social Progress, https://ec.europa.eu/eurostat/documents/118025/118123/Fitoussi+Commission+re port

[2] National Academies of Sciences, Engineering, and Medicine (2017) Valuing Climate Damages: Updating Estimation of the Social Cost of Carbon Dioxide. The National Academies Press, Washington DC. https://doi.org/10.17226/24651

[3] Simpson, R.D., Toman, M.A. and Ayres, R.U. (2005) Scarcity and Growth Revisited: Natural Resources and the Environment in the New Millennium. RFF Press, Washington DC.

[4] Vitousek, P.M., Ehrlich, P.R., Ehrlich, A.H. and Matson, P.A. (1986) Human Appropriation of the Products of Photosynthesis. BioScience, 36, 368-373.

https://doi.org/10.2307/1310258

[5] Erb, K.-H., et al. (2009) Analyzing the Global Human Appropriation of Net Primary Production: Processes, Trajectories, Implications. An Introduction. Ecological Economics, 69, 250-259. https://doi.org/10.1016/j.ecolecon.2009.07.001

[6] Wackernagel, M., et al. (2002) Tracking the Ecological Overshoot of the Human Economy. Proceedings of the National Academy of Sciences of the United States of America, 99, 9266-9271. https://doi.org/10.1073/pnas.142033699

[7] Global Footprint Network (2019) http://www.footprintnetwork.org/en/index.php/GFN/

[8] van Vuuren, D.P. and Bouwman, L.F. (2005) Exploring Past and Future Changes in the Ecological Footprint for World Regions. Ecological Economics, 52, 43-62. https://doi.org/10.1016/j.ecolecon.2004.06.009 
[9] Meadows, D.H., Randers, J. and Meadows, D.L. (2005) Limits to Growth: The 30-Year Update. Earthscan, London.

[10] Pezzey, J.C.V. and Burke, P.J. (2014) Towards a More Inclusive and Precautionary Indicator of Global Sustainability. Ecological Economics, 106, 141-154. https://doi.org/10.1016/j.ecolecon.2014.07.008

[11] Dasgupta, P. and Heal, G.M. (1974) The Optimal Depletion of Exhaustible Resources. The Review of Economic Studies, 42, 3-28. https://doi.org/10.2307/2296369

[12] Solow, R.M. (1974) Intergenerational Equity and Exhaustible Resources. The Review of Economic Studies, 42, 29-45. https://doi.org/10.2307/2296370

[13] Stiglitz, J.E. (1974) Growth with Exhaustible Natural Resources. The Review of Economic Studies, 42, 123-152. https://doi.org/10.2307/2296377

[14] Hartwick, J.M. (1977) Intergenerational Equity and the Investing of Rents from Exhaustible Resources. The American Economic Review, 67, 972-974.

[15] Weitzman, M.L. (1997) Sustainability and Technical Progress. The Scandinavian Journal of Economics, 99, 1-13. https://doi.org/10.1111/1467-9442.00043

[16] Pezzey, J.C.V. (2004) One-Sided Sustainability Tests with Amenities, and Changes in Technology, Trade and Population. Journal of Environmental Economics and Management, 48, 613-631. https://doi.org/10.1016/j.jeem.2003.10.002

[17] Dasgupta, P. (2009) The Welfare Economic Theory of Green National Accounts. Environmental and Resource Economics, 42, 3-38. https://doi.org/10.1007/s10640-008-9223-y

[18] Pearce, D.W., Atkinson, G.D. (1993) Capital Theory and the Measurement of Sustainable Development: An Indicator of "Weak" Sustainability. Ecological Economics, 8, 103-108. https://doi.org/10.1016/0921-8009(93)90039-9

[19] Hamilton, K. (1996) Pollution and Pollution Abatement in the National Accounts. Review of Income and Wealth, 42, 13-33. https://doi.org/10.1111/j.1475-4991.1996.tb00143.x

[20] Hamilton, K. and Clemens, M. (1999) Genuine Savings Rates in Developing Countries. World Bank Economic Review, 13, 333-356. https://doi.org/10.1093/wber/13.2.333

[21] World Bank (2006) Where Is the wealth of Nations? Measuring Capital for the 21st Century.

[22] World Bank (2011) The Changing Wealth of Nations: Measuring Sustainable Development in the New Millennium.

[23] World Bank (2019) World Development Indicators. http://data.worldbank.org/indicator

[24] Hanley, N., Dupuy, L. and Mclaughlin, E. (2015) Genuine Savings and Sustainability. Journal of Economic Surveys, 29, 779-806. https://doi.org/10.1111/joes.12120

[25] Nordhaus, W.D. (2017) Revisiting the Social Cost of Carbon. PNAS, 114, 1518-1523. https://doi.org/10.1073/pnas.1609244114

[26] WCED Report (1987) Report of the World Commission on Environment and Development: Our Common Future. http://www.un-documents.net/wced-ocf.htm

[27] Arrow, K.J., Dasgupta, P., Goulder, L.H., Mumford, K.J. and Oleson, K. (2012) Sustainability and the Measurement of Wealth. Environment and Development Economics, 17, 317-353. https://doi.org/10.1017/S1355770X12000137

[28] Hamilton, K. (2012) Comments on Arrow et al., 'Sustainability and the Measurement of Wealth'. Environment and Development Economics, 17, 356-361. 
https://doi.org/10.1017/S1355770X12000125

[29] Solow, R. (2012) A Few Comments on "Sustainability and the Measurement of Wealth". Environment and Development Economics, 17, 354-355. https://doi.org/10.1017/S1355770X12000113

[30] Smulders, S. (2012) An Arrow in the Achilles' Heel of Sustainability and Wealth Accounting. Environment and Development Economics, 17, 368-372. https://doi.org/10.1017/S1355770X12000174

[31] Arrow, K.J., Dasgupta, P., Goulder, L.H., Mumford, K.J. and Oleson, K. (2013) Sustainability and the Measurement of Wealth: Further Reflections. Environment and Development Economics, 18, 504-516. https://doi.org/10.1017/S1355770X13000193

[32] Hamilton, K. and Hartwick, J. (2014) Wealth and Sustainability. Oxford Review of Economic Policy, 30, 170-187. https://doi.org/10.1093/oxrep/gru006

[33] Whittaker, R.H. and Likens, G.E. (1973) Primary Production: The Biosphere and Man. Human Ecology, 1, 357-369. https://doi.org/10.1007/BF01536732

[34] UNDP HDI (2018) http://hdr.undp.org/en/content/human-development-index-hdi

[35] Nadimi, R. (2019) Relationship between Quality of Life and Energy Usage. Springer, Tokyo, Japan. https://doi.org/10.1007/978-981-13-7840-9

[36] LCA Society of Japan (2019) https://lca-forum.org/english/lime/

[37] Itsubo, N., Murakami, K., Kuriyama, K., Yoshida, K., Tokimatsu, K. and Inaba, A. (2018) Development of Weighting Factors for G20 Countries-Explore the Difference in Environmental Awareness between Developed and Emerging Countries. International Journal of Life Cycle Assessment, 23, 2311-2326. https://doi.org/10.1007/s11367-015-0881-Z

[38] Tokimatsu, K., Dupuy, L. and Hanley, N. (2019) Using Genuine Savings for Climate Policy Evaluation with an Integrated Assessment Model. Environmental and Resource Economics, 72, 281-307. https://doi.org/10.1007/s10640-018-0292-2

[39] van Vuuren, D.P., Riahi, K., Moss, R., Edmonds, J., Thomson, A., Nakicenovic, N., Kram, T., Berkhout, F., Swart, R., Janetos, A., Rose, S.K. and Arnell, N. (2012) A Proposal for a New Scenario Framework to Support Research and Assessment in Different Climate Research Communities. Global Environmental Change, 22, 21-35. https://doi.org/10.1016/j.gloenvcha.2011.08.002

[40] UN (2003) (United Nations, Department of Economic and Social Affairs, Population Division) World Population to 2300.

https://www.un.org/en/development/desa/population/publications/pdf/trends/Worl dPop2300final.pdf

[41] Nordhaus, W.D. and Yang, Z. (1996) A Regional Dynamic General Equilibrium Model of Alternative Climate-Change Strategies. The American Economic Review, 86, 741-765.

[42] Nordhaus, W.D. (2010) Economic Aspects of Global Warming in a Post-Copenhagen Environment. Proceedings of the National Academy of Sciences of the United States of America, 107, 11721-11726. https://doi.org/10.1073/pnas.1005985107

[43] Tokimatsu, K., Konishi, S., Ishihara, K., Tezuka, T., Yasuoka, R. and Nishio, M. (2016) Role of Innovative Technologies under the Global Zero Emissions Scenarios. Applied Energy, 162, 1483-1493. https://doi.org/10.1016/j.apenergy.2015.02.051

[44] Tokimatsu, K., Yasuoka, R. and Nishio, M. (2017) Global Zero Emissions Scenarios: the Role of Biomass Energy with Carbon Capture and Storage by Forested Land Use. Applied Energy, 185, 1899-1906. 
https://doi.org/10.1016/j.apenergy.2015.11.077

[45] Tokimatsu, K., Murakami, S., Adachi, T., Ii, R., Yasuoka, R. and Nishio, M. (2017) Long-Term Demand and Supply of Non-Ferrous Mineral Resources by a Mineral Balance Model. Mineral Economics, 30, 193-206. https://doi.org/10.1007/s13563-017-0109-8

[46] Tang, L., Higa, M., Tanaka, N. and Itsubo, N. (2018) Assessment of Global Warming Impact on Biodiversity Using the Extinction Risk Index in LCIA: A Case Study of Japanese Plant Species. The International Journal of Life Cycle Assessment, 23, 314-323. https://doi.org/10.1007/s11367-017-1319-6

[47] Tang, L., Ii, R., Tokimatsu, K. and Itsubo, N. (2018) Development of Human Health Damage Factors Related to $\mathrm{CO}_{2}$ Emissions by Considering Future Socioeconomic Scenarios. The International Journal of Life Cycle Assessment, 23, 2288-2299. https://doi.org/10.1007/s11367-015-0965-9

[48] Tang, L., Nagashima, T., Hasegawa, K., Ohara, T., Sudo, K. and Itsubo, N. (2018) Development of Human Health Damage Factors for PM2.5 Based on a Global Chemical Transport Model. The International Journal of Life Cycle Assessment, 23, 2300-2310. https://doi.org/10.1007/s11367-014-0837-8

[49] Tang, L., Nagashima, T., Hasegawa, K., Ohara, T., Sudo, K. and Itsubo, N. (2018) Development of Human Health Damage Factors for Tropospheric Ozone Considering Transboundary Transport on a Global Scale. The International Journal of Life Cycle Assessment, 23, 2339-2348. https://doi.org/10.1007/s11367-015-1001-9

[50] Tang, L., Furushima, Y., Honda, Y. and Itsubo, N. (2019) Estimating Human Health Damage Factors Related to $\mathrm{CO}_{2}$ Emissions by Considering Updated Climate-Related Relative Risks. The International Journal of Life Cycle Assessment, 24, 1118-1128. https://doi.org/10.1007/s11367-018-1561-6

[51] Tang, L., Ohashi, H., Hirata, A., Matsui, T., Tanaka, N. and Itsubo, N. (n.d.) Estimating Extinction Risk Factors Related to $\mathrm{CO}_{2}$ Emissions Focusing on Global Plant Species. Environmental and Science and Technology, under Review.

[52] Yamaguchi, K., Ii, R. and Itsubo, N. (2018) Ecosystem Damage Assessment of Land Transformation Using Species Loss. International Journal of Life Cycle Assessment 23, 2327-2338. https://doi.org/10.1007/s11367-016-1072-2

[53] Fankhauser, S. (1998) Valuing Climate Change: The Economics of the Greenhouse Effect. Earthscan, London.

[54] Tol, R.S.J. (2002) Estimates of the Damage Costs of Climate Change Part 1: Benchmark Estimates. Environmental and Resource Economics, 21, 47-73. https://doi.org/10.1023/A:1014500930521

[55] Tokimatsu, K., Aicha, M., Yoshida, K., Nishio, M., Endo, E., Sakagami, M., Murakami, K. and Itsubo, N. (2016) Measuring Marginal Willingness to Pay Using Conjoint Analysis and Developing Benefit Transfer Functions in Various Asian Cities. International Journal of Sustainable Development and World Ecology, 23, 541-552. https://doi.org/10.1080/13504509.2016.1168326

[56] Murakami, K., Itsubo, N, Kuriyama, K., Yoshida, K. and Tokimatsu, K. (2018) Development of Weighting Factors for G20 Countries-Part 2: Estimation of Willingness to Pay and Annual Global Damage Cost. The International Journal of Life Cycle Assessment, 23, 2349-2364. https://doi.org/10.1007/s11367-017-1372-1

[57] Kolstad, C., Urama, K., Broome, J., Bruvoll, A., Cariño Olvera, M., Fullerton, D., Gollier, C., Hanemann, W.M., Hassan, R., Jotzo, F., Khan, M.R., Meyer, L. and Mundaca, L. (2014) Social, Economic and Ethical Concepts and Methods. In: Edenhofer, O., Pichs-Madruga, R., Sokona, Y., Farahani, E., Kadner, S., Seyboth, K., 
Adler, A., Baum, I., Brunner, S., Eickemeier, P., Kriemann, B., Savolainen, J., Schlömer, S., von Stechow, C., Zwickel, T. and Minx, J.C., Eds., Climate Change 2014: Mitigation of Climate Change. Contribution of Working Group III to the Fifth Assessment Report of the Intergovernmental Panel on Climate Change, Cambridge University Press, Cambridge, United Kingdom and New York.

[58] IIASA (2015) SSP Database. https://ntcat.iiasa.ac.at/SspDb/dsd?Action=htmlpage\&page=about

[59] UN 2011 UNDESA Population Division (United Nations, Department of Economic and Social Affairs, Population Division) (2011) World Population Prospects: The 2010 Revision, Highlights and Advance Tables. ESA/P/WP.220 UNDP HDI. http://hdr.undp.org/en/content/human-development-index-hdi

[60] Purdue University (2019) https://www.gtap.agecon.purdue.edu/

[61] Berndt, E. and Wood, D. (1975) Technology, Prices, and the Derived Demand for Energy. The Review of Economics and Statistics, 57, 259-268. https://doi.org/10.2307/1923910

[62] Manne, A.S. and Richels, R.G. (1992) Buying Greenhouse Insurance: The Economic Costs of Carbon Dioxide Emission Limits. MIT Press Cambridge, MA, and London, England.

[63] Nordhaus, W.D. and Boyer, J.G. (2000) Warming the World: Economic Models of Global Warming. The MIT Press, Cambridge, MA, and London. https://doi.org/10.7551/mitpress/7158.001.0001

[64] Portney, P.R. and Weyant, J.P. (1999) Discounting and Intergenerational Equity. RFF Press, Washington DC.

[65] Stern, N. (2006) Stern Review: The Economics of Climate Change. Cambridge University Press, Cambridge, UK. https://doi.org/10.1017/CBO9780511817434

[66] Dasgupta, P. (2008) Discounting Climate Change. Journal of Risk and Uncertainty, 37, 141-169. https://doi.org/10.1007/s11166-008-9049-6

[67] Nordhaus, W.D. (2007) A Review of the Stern Review on the Economics of Climate Change. Journal of Economic Literature, 45, 686-702. https://doi.org/10.1257/jel.45.3.686

[68] Psacharopoulos, G. (1994) Return to Investment in Education: A Global Update. World Development, 22, 1325-1343. https://doi.org/10.1016/0305-750X(94)90007-8

[69] Hall, R.E. and Jones, C.I. (1999) Why Do Some Countries Produce so Much More Output Per Worker than Others? The Quarterly Journal of Economics, 2, 83-116. https://doi.org/10.1162/003355399555954

[70] Psacharopoulos, G. and Patrinos, H.A. (2004) Returns to Investment in Education: A Further Update. Education Economics, 12, 111-134. https://doi.org/10.1080/0964529042000239140

[71] Lutz, W., Goujon, A., Samir, K.C. and Sanderson, W. (2007) Reconstruction of Populations by Age, Sex and Level of Educational Attainment for 120 Countries for 1970-2000. Vienna Yearbook of Population Research, 193-235.

https://doi.org/10.1553/populationyearbook2007s193

[72] Barro, R.J. and Lee, J.-W. (2010) A New Data Set of Educational Attainment in the World, 1950-2010. NBER Working Paper No. 15902. https://doi.org/10.3386/w15902

[73] Klenow, P.J. (2005) Externalities and Growth. In: Aghion, P. and Durlauf, S., Eds., Handbook of Economic Growth, Elsevier, North-Holland, 817-861.

https://doi.org/10.1016/S1574-0684(05)01011-7 
[74] Wigley, T.M.L., Richels, R. and Edmonds, J. (1996) Economics and Environmental Choices in the Stabilization of Atmospheric $\mathrm{CO}_{2}$ Concentrations. Nature, 379, 240-243. https://doi.org/10.1038/379240a0

[75] Uchijima, Z. and Seino, H. (1985) Agroclimatic Evaluation of Net Primary Productivity of Natural Vegetations (1) Chikugo Model for Evaluating Net Primary Producticity. Journal of Agricultural Meteorology, 40, 343-352. https://doi.org/10.2480/agrmet.40.343

[76] Ferreira, S., Hamilton, K. and Vincent, J.R. (2008) Comprehensive Wealth and Future Consumption: Accounting for Population Growth. The World Bank Economic Review, 22, 233-248. https://doi.org/10.1093/wber/lhn008

[77] Wigley (2010) http://www.cgd.ucar.edu/cas/wigley/magicc/

[78] Nordhaus, W.D. (1979) The Efficient Use of Energy Resources. Yale University Press, New Haven, CT.

[79] Gordon, R.B., Koopmans, T.C., Nordhaus, W.D. and Skinner, B.J. (1987) Toward a New Iron Age? Quantitative Modeling of Resource Exhaustion. Harvard University Press, Cambridge, MA. 


\section{Appendix: A List of Notations}

\begin{tabular}{|c|c|c|}
\hline \multirow[t]{5}{*}{ Exogenous data } & $A$ & Total factor productivity (TFP), used as a calibration factor, similar to the Solow residual \\
\hline & $L$ & Labor force (population aged 15-64) \\
\hline & $\mathrm{Neg}$ & Negishi weight \\
\hline & $P$ & Population \\
\hline & $\bar{Y}$ & Reference GDP from marker scenarios of Shared Socioeconomic Pathway (SSP) \\
\hline \multirow[t]{28}{*}{ Endogenous variables } & $C$ & Aggregate consumption \\
\hline & $c$ & Aggregate consumption per capita \\
\hline & $E L$ & Electricity \\
\hline & $E X T$ & Environmental external cost \\
\hline & $F$ & Production function \\
\hline & $F C$ & Cost of fuel minerals (energy) supply chain \\
\hline & $G S$ & Genuine Savings \\
\hline & $H$ & Aggregate stock of human capital \\
\hline & $I$ & Investment in the physical capital \\
\hline & InV & Inventories like $\mathrm{CO}_{2}, \mathrm{SO}_{\mathrm{X}}, \mathrm{NO}_{\mathrm{X}}$, extraction and disposal of non-fuel minerals, and land cover change \\
\hline & $K$ & Aggregate stock of physical capital \\
\hline & $L C$ & Cost of land use and land use change with food and biomass supply chain \\
\hline & $L R$ & Land resources \\
\hline & $M$ & Non-fuel mineral resources \\
\hline & $N E$ & Non-electric energy resources \\
\hline & $N F C$ & Cost of non-fuel minerals supply chain \\
\hline & $s$ & time for integration \\
\hline & $S$ & Average education years \\
\hline & $S P$ & Shadow prices of all capital forms \\
\hline & $t$ & continuous time \\
\hline & $T C$ & Total cost; sum of $F C+N F C+L C$ \\
\hline & $U$ & Aggregated utility \\
\hline & $u$ & per capita utility \\
\hline & $V$ & Social welfare, inter-temporal well-being \\
\hline & $W$ & Global social welfare, comprehensive wealth \\
\hline & $W^{O B / W B}$ & Wealth accounted by adjusted consumption, outcome based (OB) by the World Bank Group \\
\hline & $X$ & Mined products input to processing \\
\hline & $Y$ & Net output \\
\hline \multirow[t]{8}{*}{ Constant parameters } & $D R$ & Damage factors expressing Dose-Response relations in the lifecycle assessment model LIME \\
\hline & $M W T P$ & Weighting factors derived from marginal willingness to pay (MWTP) in LIME \\
\hline & $T$ & Time to sum over years to obtain intertemporal well-being \\
\hline & $\delta$ & Annual rate of physical capital depreciation, set as $0.07-0.18$ \\
\hline & $\eta$ & Elasticity of marginal utility of consumption, default set as 1.5 \\
\hline & $\phi$ & Individual human capital stock by education \\
\hline & $\rho$ & Pure rate of time preference, default set as 0.015 \\
\hline & $\tau$ & TFP growth rate \\
\hline
\end{tabular}

